\title{
Improving Professional Learning and Teaching Through the Development of a Quality Process
}

\author{
Jennifer Rowley (Corresponding author) \\ Sydney Conservatorium of Music, The University of Sydney, \\ Building C41, Sydney 2006 NSW, Australia
}

Tel: +61-2-9351 1328 E-mail: jennifer.rowley@sydney.edu.au

Lesley Scanlon

School of Education and Social Work, The University of Sydney

Building A25, Sydney 2006 NSW, Australia

Tel: +61-2-9351 1295 E-mail: lesley.scanlon@sydney.edu.au

\section{Lesley Laing}

School of Education and Social Work, The University of Sydney

Building A25, Sydney 2006 NSW, Australia

Tel: +61-2-9351 1346 E-mail: lesley.laing@sydney.edu.au

\section{Lorraine Smith}

Faculty of Pharmacy, The University of Sydney, Building A22, Sydney 2006 NSW, Australia Tel: +61-2-9351 $1283 \quad$ E-mail: lorraine.smith@sydney.edu.au

\section{Lesley Treleaven}

School of Economics, The University of Sydney, Building A13, Sydney 2006 NSW, Australia Tel: +61-2-9351 1251 E-mail: lesley.treleaven@sydney.edu.au

Received: November 24, 2013 Accepted: December 19, 2013 Published: December 21, 2013 doi:10.5296/jet.v1i1.4612 URL: http://dx.doi.org/10.5296/jet.v1i1.4612 


\section{Abstract}

Investigation of graduate attributes (GAs) and professional standards (PSs) within faculty curriculum development are rare, despite university importance. Examining learning objectives and assessment with PSs and accreditation, this project sought learning and teaching improvements through developing a cross discipline quality assurance process, aligning learning and assessment with PSs and GAs. This paper describes the results of interviews with those responsible for teaching and learning in four faculties at an Australian University. The results indicate that curriculum developers are often unable to align the GAs and PSs that creates challenges for an assurance of students' learning.

Keywords: higher education, professional learning, quality process, professional standards, graduate attributes, curriculum objectives

\section{Introduction and Background}

A joint project ${ }^{1}$ between the Faculties of Education and Social Work (EDSW), the Sydney Conservatorium of Music (SCM), Economics and Business (E\&B) and Pharmacy (FoP), aimed to improve university-based professional learning and teaching across these faculties in five professional practice degree programs. There were five specific aims: to develop a model for auditing the alignment between learning objectives, outcomes and assessment with Professional Standards (PSs) and Graduate Attributes (GAs); to employ this model for auditing the alignment across the four faculties (BCom, BPharm, BSW, MTeach [Sec] and BMus [Music Ed]); to identify how and where quality assurance processes ensure the alignment of curriculum outcomes with PSs and GAs which could involve developing a process applicable across programmes and faculties to promote quality assurance aimed at curriculum alignment; to collect evidence samples from each faculty in the project to identify quality processes that assure learning and their cross-faculty application and; to identify quality assurance processes in the four faculties that align curriculum outcomes with PSs and GAs. Following is a literature review that explains the concepts of graduate attributes, professional standards and assurance of learning within the context of the project results presented in this paper.

\subsection{Graduate Attributes (GAs)}

Johnston and Watson (2004) articulate the limitations of a 'key skills' agenda (keys skills is a UK term for GAs) as a guide to curriculum practice, and argued that higher education has changed from an 'academic-led "supply" model to an employer-led "demand" model of higher education' (2004, p. 54). Furthermore, graduates required more than just a list of key skills; they needed to entail elements of self-awareness, self-efficacy and emotional intelligence. Graduates' feelings of inadequacy manifest themselves when they are unprepared for real world employment experiences. Barrie (2006) examined academic conceptions of GAs, arguing that universities need to produce more employable graduates. Barrie's (2006) research with academics from 14 disciplinary backgrounds across five broad fields of study identified: 'Four increasingly complex, qualitatively distinct understandings' (2006, p. 223) - precursory, complementary, translation and enabling conceptions. 
'Enabling conception' allows 'abilities and aptitudes that lie at the heart of scholarly learning and knowledge with the potential to transform the knowledge they are at of and support the creation of new knowledge' (Barrie, 2006, p. 223).

Barrie (2006) argued that GAs should be explicit and articulated and also that the variations in conceptualisations of GAs across the disciplines would suggest that discipline alone does not account for the observed variation, an area for further research. Barrie (2007) extends this by presenting his analysis of data on academics' understanding of how students acquire generic attributes. Six distinct categories were identified: remedial, associated, teaching content, teaching process, engagement, and participatory. The first two were seen as supplementary to the curriculum while the others are integrated into the curriculum, or 'nested' or 'inclusive' (Barrie, 2007, pp. 449-450). He suggested that this framework was a useful tool for dialogue about a range of initiatives to achieve graduate outcomes. It is clear that GAs are universal and that many Higher Education institutes struggle to manage them appropriately.

Treleaven and Voola (2008) focused on universities seeing GAs as a part of a 'process' in higher education as Universities needed proactive strategies for developing GAs. They argued that the key GA is student's ability to analyse future-orientated issues, concentrating on critical thinking and critical reflection skills, creating a basic framework for constructive alignment of GAs with assessment criteria. Treleaven and Voola (2008) highlighted the process of integrating two GAs through constructive alignment into a Master's level marketing strategy course, evaluated using an action research approach. This offered a number of very relevant recommendations to integrate GAs into the current university curriculum. Of the four faculties that investigated in this project, most had attempted to embed the GAs into the curriculum.

Harvey and Kamvounias (2008) used theories of change management and contemporary educational theories (constructive alignment and deep and surface approaches to learning) to evaluate a policy initiative that aimed to encourage subject coordinators to use a (Business) faculty-endorsed template to embed GAs into their subject outlines. They explored the 'implementation gap' between policy and application and made recommendations for future efforts to embed GAs in the curriculum and argued that learning and teaching theories promoting student-centred teaching are usually applicable, advocating a parallel 'teacher-as learner' model for embedded curriculum GAs (Harvey \& Kamvounias, 2008, p. 37). This is very relevant to the project described in this paper, as it is a case study that looks at the process of embedding GAs in the curriculum.

Edwards (2005) argued that GA development required creating and designing a student-centred learning approach, where lecturers remained informed with the various postgraduate employment industries. Edwards (2005) noted that lecturers needed to control the delivery of course material to realise the actualisation of GAs and the enactment of contemporary pedagogy.

Bath, Smith, Stein and Swann (2004) presented arguments related to the project outlined in this paper when they described Universities as needing to acknowledge differences between 
espoused curricula and the taught curricula. Bath et al. (2004) concurred with Treleaven and Voola (2008) commenting that "generic skills should represent the central achievements of higher education as a process” (p. 313). This process encourages an 'intellectual curiosity' and an outcomes measure development as part of the quality movement with GAs including a process of planning, action, reviewing and reflecting. Quality teaching and learning is key to the successful attainment of the GAs.

\section{Assurance of Learning (AoL)}

Higher Education is seeking an AOL through well planned and appropriate curriculum design. Berdrow's study (2008, p. 288) followed the redesign of an introductory business course "based on AoL (that is, assessment) principles" in North America. Although the final examination assessment showed that students had learnt and applied the key course concepts, student course satisfaction measures were much lower than normal. She concluded that a learning objective foci resulted in the adoption of a "rigid, content-driven teaching style" (Berdrow, 2008, p. 15) rather than facilitating learning through student relationships and interaction. The conclusion was that: "The lesson I learned was that designing and delivering course content in order to achieve desirable learning outcomes is about facilitating learning, not about mechanical teaching” (Berdrow, 2008, p. 16). It is important that Higher Education teachers examine their practices in relation to measurable outcomes achieved by students. This requires an assurance that the learning undertaken is student-centred, inquiry based and contextual.

"For each degree program, learning goals must be articulated, and evaluated through direct measure." (Pokharel, 2007, p. 241). Of the term 'direct measure' (students' demonstration of their learning compared to survey of student satisfaction), one interviewee in the project discussed in this article made a key point that an essential step in the process is to use assessment data for curricular improvement, also referred to as "closing the loop" (Pokharel, 2007 , p. 242). Numerous examples are provided of implementable measures for curricular improvement, with the interviewee adding that there should be concern to eliminate anxieties of individual teacher assessment through AoL, and urging a focus on assessment methods that produce data which lead to curricular improvement - improvements that build upon existing practice and, rather than excessive focus on complex assessment methodologies, and that do not increase workloads. An AOL can be discovered through student evaluations but also via student created portfolio work (for example). Oliver (2011) discussed how ePortfolios can be used as an AoL tool within a curriculum for graduate employability, linking PSs and work-integrated learning within a 360-degree evidence based approach. Whilst De la Harpe and Radloff (2008) proposed a GA development framework for life-long learning, with centrality of academic engagement a key argument, drawing upon links with Barrie's (2006, 2007) argument of academic conception. Strategies and resources are required to embed GAs should exclude a top-down 'managerialist' approach or a 'how-to' guide for change.

\section{Cross Discipline Professional Standards (PS) and Accreditation}

McNay's UK based survey in 2007, explored academics' views on underpinning higher education values, and on the current situation of PS and their introduction into curricula. The 
findings in this discussion, of the various dimensions of 'managerialism', and the ways in which this challenges 'traditional' values about higher education (while cautioning against viewing the past with rose coloured glasses), is relevant where the exploration is contextually similar to this research.

As there were four faculties involved in this study the following literature relates specifically to each discipline's relationship to GAs, PSs and AoL.

\subsection{Social Work}

Stoesz and Karger (2009) sharply critiqued the Council on Social Work Education (CSWE) accreditation of American social work courses, contending a contribution to the "professional decline' of social work. Based in Australia within a social work program, Cameron (2001) explored the role of professional associations in accrediting university programs with reference to law, medicine, physiotherapy, social work, teaching and psychology. She also explored issues of the accountability of universities for educating these professionals, concerned with AoL at the wider level. Cameron (2008) argued that where university teachers are active members of professional associations (as they are in the school of social work), close relationships can jeopardise standards. In essence, '... the processes of accreditation are deeply flawed, and contribute to the difficulties that universities experience in targeting professional education programmes to meet the demands of employers and society in general' (Cameron, 200, p. 288). A decade later, Morley and Macfarlane (2010) critiqued the move by the Australian Association of Social Work (AASW), the accrediting body for social work degrees, to identify both priority areas for curriculum and explicit context within these. Taking the example of the AASW requirements for social work education about mental health, they argued that required curriculum constructs social work narrowly in terms of technical competencies and colluded with existing power hierarchies that defined mental illness in terms of individual pathology, an approach out of keeping with social work's critical tradition and commitment to promoting social justice. The results of this study presented here support these findings by Morley and Macfarlane (2010).

\subsection{Business}

A similar theme about curriculum 'ownership' was cited in a number of North American articles about the new Association to Advance Collegiate Schools of Business International (AACSB) accreditation standards. Kilpatrick, Dean and Kilpatrick (2008) argued, that the new accreditation standards are leading to a situation where:

"We observe that business schools are moving away from the liberal model of holistic education toward more demonstrable, discrete skills-based training, at least in part because of the idea that education's aims may reasonably be captured with lists of learning objectives and corollary skill sets that demonstrate these objectives." (p. 200)

Pokharel's 2007 research (discussed above) is part of this on-going change process associated with the introduction of new AACSB standards, as she attempts to address educators' anxiety about the implications of the changed accreditation requirements. The issue about changing industry accreditation procedures haunts many Higher Education course designers, as there is 
constant tension between industry and educators.

\subsection{Education}

Beck (2008) provided an analysis of "a relatively coherent governmental project, spanning the decades of Conservative and New Labour government in England since 1979, that has sought to render teachers increasingly subservient to the state and agencies of the state" ( $\mathrm{p}$. 119). Employing different tactics - discrediting teachers and attempting to win teachers' support for a new model of teacher 'professionalism' - the movement was seen as part of a coherent project. This is relevant to the current project, in questioning what 'standards' mean in the context of 'government professionalism'. 'I argue that the discourse of the 'standards' is dangerous, not least because it has the sinister capacity 'to marginalize and even silence competing ideas precisely by not entering into debate with them but instead by tacitly presuming their irrelevance' (Beck, 2009:119).

Challenging the legitimacy of PSs to university teaching in this context is challenging the role of government in setting standards, rather than professional associations. Gillard (2005) made a similar argument, that is, that New Labour has extended the process of de-professionalization. Gillard (2005,) said hopes that the election of New Labour would reverse the Tory attacks on teacher professionalism were dashed, arguing, like Beck, that New Labour extended the attack with 'national literacy strategies' and 'national learning targets' that had begun under the previous Conservative governments (p. 117).

\subsection{Pharmacy}

Kelley, McAuley, Wallace and Frank (2008) looked at the alignment of accreditation standards with the curriculum, describing the process and application of curriculum mapping, and provides a case study as an example. Curriculum mapping is an accreditation required element of program-level assessment. However, as described in this paper, curriculum mapping is also a quality assurance tool, providing information on the curriculum and identifying areas for improvement.

In summary, the literature reviewed contains researchers' work addressing the challenges, and possible processes, for embedding GAs in professional education curricula. However, with respect to the alignment of PSs and learning outcomes and assessment, we enter more contested territory. For several professional groups, a debate surrounds the standards and relationship of those setting the standards and the universities conducting professional education: for example, the perceived governmental imposition of a narrow, content-based approach to PSs (as in education) or perceived illegitimacy of an accrediting body (as in social work), this contested issue of who defines the standards and how legitimate they are, is fore grounded in the literature. This is also seen in some of the business literature. Again we confront the issue of the different contexts for the different professional groups (both in Australia and internationally) that has emerged in in the results of the project discussed in this article. 


\section{Methodology}

As this is an investigation into the quality of Gas, PS's and AOL in each of the four faculties it is important to view the findings as indicative of the current situation at one higher education institution in Australia. The study adopted a qualitative approach and survey and interview data were analysed for themes. The research literature informed the development of the survey and interview instruments, which were trialled and refined before being adopted for use across the four research sites. Recognising that the anonymity of a questionnaire "encourages greater honesty" (Cohen, Manion \& Morrison 2001, p. 128), each survey for the eight participants included closed questions, open questions, and repeated items for the purpose of triangulation. Each participant also attended a semi-structured interview. Textual data were transcribed, coded and analysed for emergent themes.

The academics responsible for each discipline's accredited programs, all either program directors or associate deans in education, social work, accountancy, business, pharmacy, or music education, were identified and requested to participate in an interview. All participants were interviewed either by the research assistant or a team member, with interviews lasting between 45 minutes and 90 minutes. There were 15 questions in a semi-structured interview. Sampling was purposive and ethics was gained for the collection of the interview data. Audio recordings of the interviews were transcribed and checked for accuracy by interviewer and interviewee.

\subsection{Participants}

Eight participants were interviewed representing the four faculties. Their identities have been protected, and are listed below:

Participant 1 and $2 \quad$ Sydney Conservatorium of Music (SCM)

Participant 3 and $4 \quad$ Faculty of Economics and Business (E\&B)

Participant 5 and $6 \quad$ Faculty of Pharmacy (FoP)

Participant 7 and $8 \quad$ Faculty of Education and Social Work (EDSW)

\subsection{Data Analysis}

The interview transcripts were collated by question, and assembled into three sections: GAs, PSs, and AoL. Two team members coded responses to each data set independently for themes. Following independent coding, the two research team members together analysed the data thematically. One team member recorded the thematic analysis for their section, which was then peer reviewed. The research team discussed all drafts and the agreed data interpretation was written up by one of the pairs and reviewed by another pair member before collating the full draft and circulating it for review by the research team. The following results can be seen as a case study in how GAs, PS's and AOL are evidenced across the four faculties.

\section{Results}

Responses to the question 'how important are the University's GAs in your curriculum 
design?' highlighted three key areas of course of study development: graduate attributes, faculty specific course design, and implementation processes and accreditation methods. In describing these key areas, the interviewees demonstrated cross-faculty differences in their perceptions, processes and accreditation methods, and differing 'in-faculty' tension between the key elements.

\subsection{GAS}

In the first key area, 'specificity' of GAs, Participant 1 (SCM) described how, after wide consultation with staff, and outcomes from different learning and teaching committees, the SCM 'drew up its own faculty's graduate attributes'. SCM GAs were based upon, and aligned with, University GAs. However, the SCM's decision to design a faculty-specific set of GAs suggests that either University GAs are not specific enough to provide an adequate basis for curricula design (including evidence for AoL), or that some disciplines require additional GAs for definition and inclusion into the curriculum.

Participant 4 (E\&B), focusing on program integrity and differentiation, also described the lack of GA specificity, suggesting that, if every program sought to meet the University's 'five very generic, very wide graduate attributes', there would not be any program differentiation. Instead, differentiation combines University GAs and 'more specific quasi-technical professional learning content'. Similarly, Participant 6 (FoP) argues that they are 'a lot more generic than our professional standards'.

Describing the introduction of PSs in Education in NSW over the past two years, Participant 8 (EDSW) argued that the GA focus had shifted. Previously the faculty tried to 'embed the graduate attributes in our units of study'. Now, after state government implemented PSs, 'they are certainly not up front for us any more'. Based on the above participant comments regarding faculty-derived GAs for curriculum development, as opposed to generic University GAs, there appears to be consensus between faculties (SCM, E\&B, and FoP). However, there were mixed views about whether the generic University GAs contributed positively or negatively to curricula development in the FoP. Participant 6 indicated that University GAs were 'very important' to curriculum design. Moreover, the FoP was reviewing the curriculum to ensure that all of the revised learning outcomes were 'based on professional standards as well as the graduate attributes'. Similarly, Participant 5 (FoP) stated that University GAs are 'such professionally appropriate commentaries' they would have included them in the degrees 'anyway'.

The SCM's decision to create faculty-specific GAs suggested greater neutrality. On their own, University GAs are not entirely sufficient for curriculum design. Participant 1 indicated they 'felt it was appropriate that the faculty design its own', as they were 'considered important', but they are sufficient enough that these new GAs were 'based on the University's'. More negatively, Participant 4 indicated that GAs were so generic that, upon multiple program application, course-specific GAs ended up looking 'too much alike'. Moreover, the faculty approach to course design was to 'put the university GAs aside'. In short, if the course coincides with the University GAs then 'fantastic', otherwise 'it does not matter'. Suggesting that University GAs affect course differentiation, Participant 4 took a more 'literal' approach 
to interpreting University GA implementation. This is contrasted to the other respondents, particularly those from the SCM. This 'literal' interpretation of GAs could be counter-productive to their implementation. However, in response to the question 'How are professional standards aligned with graduate attributes?' participant 4 contextualized his position describing a 'push-pull' relationship between: program branding and marketing, 'value to prospective students', and program integrity. The first responses two relate to GAs.

\subsection{GA Communication}

Importantly, only interviewees from E\&B explicitly mentioned program branding and marketing as fundamental to course design. This emphasises a discipline-specific approach to course design: for example, in response to the question 'Tell me about professional standards and how much influence they have on the teaching of [CPA] here?', Participant 3 indicated that "stakeholders" interested in the benchmarking between universities for non-professional standards "would be potential students". Noticeably, in E\&B, GAs as learning outcomes is an important marketing tool for attracting potential students.

Equally, the importance placed on the communication of GAs by E\&B is also found within EDSW. In this, handbooks are an important marketing tool. Participant 7 (EDSW) described the practice of Social Work students spending time with practitioners in the field. These handbooks contain the "goals or vision for the University's social work program", information regarding the Australian Association of Social Workers, and "graduate attributes". However, the handbooks are primarily aimed at 'teaching them [practitioners] about what it is that forms our program', rather than potential students. Similarly, other faculties also placed importance on the communication of GAs, but with more internal focus compared to E\&B and EDSW. Participant 1 (SCM) indicated a concern' about how the faculty 'sell' GAs, stating that 'students lose sensitivity' to them and do not really understand what GAs are. In response to the question 'How are professional standards aligned with graduate attributes? Is this currently at program and/or unit of study level?', Participant 2 (SCM) indicated that, in unit of study handouts, 'there is a separate section where the graduate attributes are listed'. Consequently, 'students can actually see what the subject is trying to do'. Similarly, regarding curriculum review and design, Participant 5 said, historically, the FoP had not 'made it obvious to the student' that they will have certain graduate attributes, but hope to communicate GAs to students in the future. Noticeably, faculties assigned importance to University GAs differently based on specificity. Nevertheless, it is widely accepted that GAs were an important consideration in curriculum design. However, importance is placed on a faculty's ability to communicate GAs, and having an appropriate framework to communicate them, depending upon discipline and purpose.

\subsection{Interpretation of PSS}

It was widely agreed that 'professional standards' were important to each faculty for program design, implementation, and assurance (in the form of AoL). However, professional standards differed across each of the four faculties depending upon the standards themselves, their interpretation, and a faculty's obligations to those standards. 
Participant 1 (SCM) described PSs as an indication of 'what's perceived to be good practice' in Music Education. In Performance programs, standards are developed based on the instrument being studied and the unit of study (i.e. keyboard, brass, etc.). Thus, 'standards are very much determined within that unit'. These standards are defined in consultation with unit staff and 'professional stakeholders - so the SSO [Sydney Symphony Orchestra] the Department of Education, Opera Australia chamber music groups, the whole spectrum of employment'.

Participant 3 (E\&B) supports this perception but is more detailed, describing industry links with professional standards as 'areas' that accrediting bodies 'believe that the professional bodies believe that somebody entering the accounting profession should have'. Equally, Participant 7 regarded PSs as a 'set of standards that apply to practitioners, and they were developed around standards for practice'. Similarly, Participant 5 (FoP) supports this view, describing graduates as 'safe, competent practitioners' who are 'fit to practice' and have met the relevant 'state and national requirements'. This suggested the FoP distinguish between mandatory state and national requirements and graduate competency, although attribute both to aspects of development to PSs. The above examples show that the FoP is industry-aligned. Equally indicative of this, Participant 3 (E\&B), discussing program design, states that PSs are concerned 'with the scope of the content and also the development of generic skills'. Describing how professional standards influence program design, Participant 4 (E\&B) stated they influence the 'content to some extent, perhaps not as sharply as they should' and 'professional standards are more implicit in some programs than in others'. This suggested, as we have seen with GAs, a lack of specificity with some of the faculty's PSs and that the level of specificity is course dependent. As a member of the social work accrediting body, the faculty of EDSW placed importance on the interpretation of PSs. Participant 7, regarding the current national standard review, stated 'my hope is that we'll be able to come to an agreement where the national standards are clear in our field education'.

In contrast, Participant 6 (FoP) stated that the accrediting body (Pharmaceutical Society of Australia) has 18 standards and, within each standard, 'they have several criteria and each criteria would have indicators'. Participant 7 argued that these variegated criteria and indicators are useful for course design: 'I access all of those to find out what are the standards and how I can kind of address some of those within the course'. Interestingly, despite the FoPs obligation to PSs, and the inclusion of PSs in program development, Participant 6 stated that the faculty is 'not obliged to produce students that meet all of the professional standards'. Rather, according to Participant 5 (FoP), successful accreditation permits the faculty to offer the degrees'.

Conversely, Participant 7 (EDSW) argued that, for social work, PSs are now 'completely embedded in the national education accreditation policy'. As a result, the faculty's obligations to the PSs are indirectly enforced: 'all social work programs have to meet the requirements of the national policy'.

In response to the question 'tell me about professional standards and how much influence they have on the teaching of music education here?' participant 1's response is indicative, 
particularly as there were no significant program changes required for accreditation because the programs met requirements. SCM were, however, required 'to demonstrate that our programs meet those requirements'. Moreover, before the accreditation process there 'were standards that were mandated but not necessarily documented as clearly by the DET'.

Participant 8 (EDSW) described the inclusion of NSWIT PSs in faculty programs. We must 'assure the Institute that we do this, through our documentation'. Moreover, when the faculty re-applies for accreditation 'we have to put up our documents again and we have to put them in the language of the institute'. This demonstrates the rigidity of the documentation process in Education.

\subsection{Accreditation Methods}

Accreditation processes varied across faculties due to the dynamics of the accrediting bodies and the discipline. Furthermore, program variation caused intra-faculty differences in accreditation processes. Participant 8 (EDSW) argued that the education accrediting body 'does not relate to students in any way at all', in that unlike social work samples of student work were not submitted to the institute. Instead, it awarded accreditation based on faculty documentation: 'we put in about 1,000 pages of documentation for one course'. This documentation is 'proof that students when they graduate from our programs have met all of the standards in the mandatory areas'.

Participant 6 (FoP) described a similar experience, stating PSs are 'all done by the profession so they will be done through the Pharmaceutical Society of Australia (PSA), so they have their standards'. Despite PSA accreditation, Participant 6 stated that, upon completion of a Pharmacy degree, students 'graduate, but they have to go and do 2,000 hours of supervised practice and sit exams run by the board' to become professionally accredited. Additionally, 'the 12 months that they are out as graduates has nothing to with the university'. Noticeably, in Education the course is accredited whereas in Pharmacy the individual is accredited. Regarding formality, 'formal' accreditation includes, as a key discriminator, external accrediting bodies independent of the University, engaging in consultation processes for standards by acting as agent between industry and/or education. Conversely, 'informal' accreditation has no accrediting body. Rather, the consultation process, to establish standards and links between education and industry, is managed by the university or faculty. The differences between the faculties in accreditation 'formality' and accreditation type can be seen in the 'Accreditation Matrix' in Figure 1. 


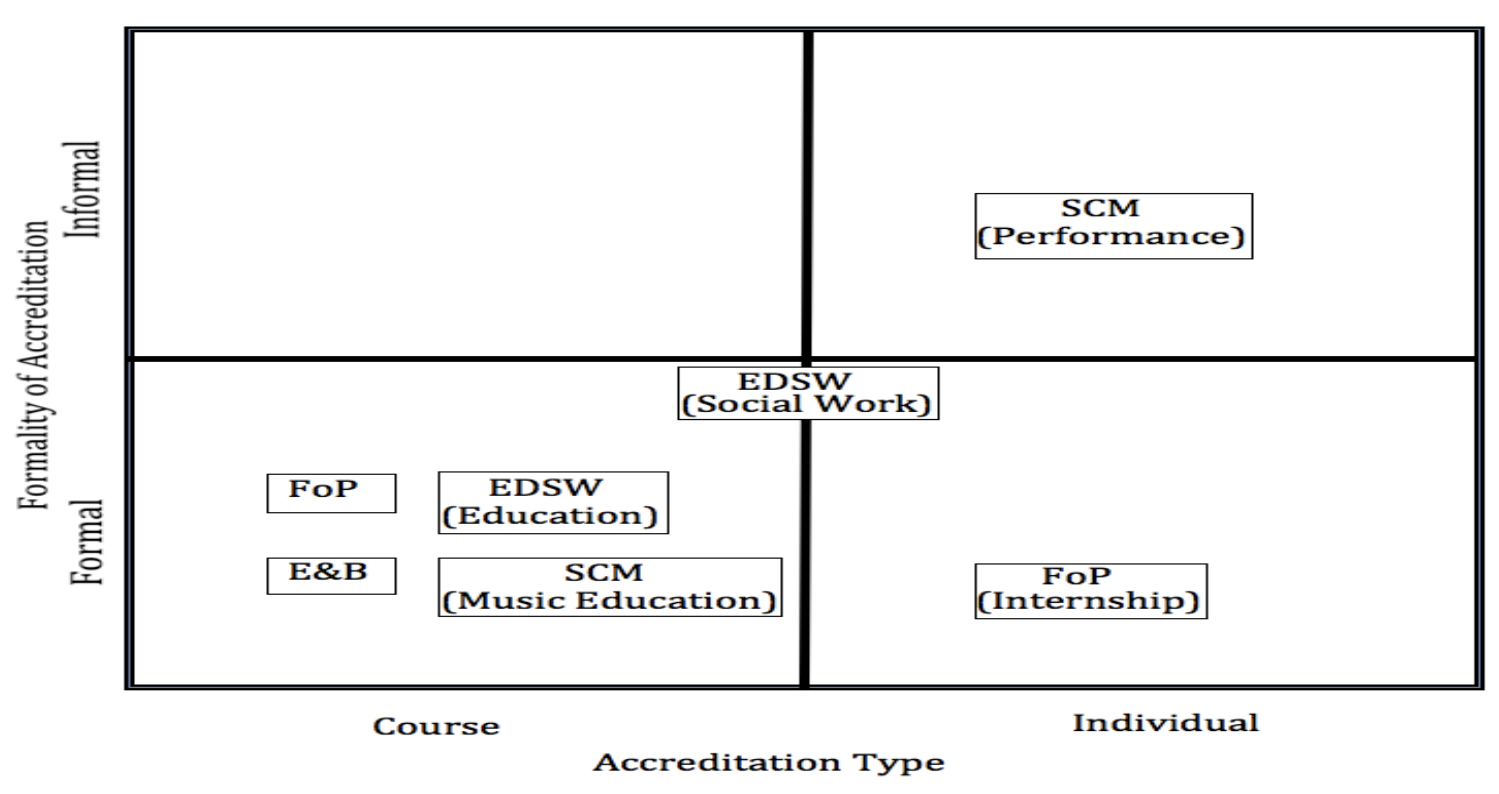

Figure 1. Accreditation Matrix showing the faculties' accreditation formality vs. type

Having looked at SCM's 'informal' approach to accreditation in performance-based programs, Participant 2 (SCM) describes the process of NSWIT accreditation for Music Education programs: 'there's a panel that sees whether they feel that the particular degree meets those standards'.

In this instance, the course is accredited not the individual, thereby demonstrating an intra-faculty difference in accreditation formality and type. Similarly, in EDSW, the Education and the Social Work programs require course accreditation. However, Social Work students must complete a 'field education' component with a qualified 'field educator'. Participant 7 (EDSW) said: 'in Field Education 1, they do 60 days so a whole semester and in Field Education 2, they do a semester and a bit - 80 days'.

The Accreditation Matrix (Figure 1.) is a useful tool for plotting changes in faculty accreditation formality over time: for example, prior to 2007 NSWIT accreditation, SCM Music Education had no formal external accreditation. This suggests, prior to accreditation, SCM Music Education followed an 'informal' approach. However, there was little need for program content change as the course conformed closely to the new accreditation.

\subsection{Program Integrity}

Participant 4 (E\&B) used the term 'program integrity' to describe program differentiation. It can be interpreted as the solidity and robustness of content against external elements, and the value of an individual program distinct from other programs within the same faculty. Content robustness is typically measured through assurance of learning (AoL), with benchmarking processes being done either internally or externally.

In response to 'what are the processes that oversee these standards?' participant 8 (EDSW) 
said that the faculty must provide documentation to NSWIT proving that 'each of the standards are embedded' and all 'mandatory areas have also been covered' in each curriculum area. Failure to meet these requirements means that faculty 'programs are not accredited'. First, placing University GAs in an external framework is 'too complex'. Second, faculty focus is on acquiring course accreditation to operate courses and teach students.

Equally, Participant 5 (FoP) stated that the national accrediting body has a 'very direct influence' on teaching but the faculty's ability to run a course is not solely dependant on accreditation. Rather, the faculty aims to 'offer degrees that will be recognized by the profession'. This is apparent in new degrees where 'formal accreditation for a degree can't actually be completed until there are graduates of the degree'. FoP accreditation is described as 'fairly intense'. New degrees must acquire accreditation prior to commencement, and then must be reassessed after graduate enrolment. In essence, a course is accredited twice in three years, with full accreditation after 'a maximum of five years'.

Accreditation in EDSW and FoP differs in professional recognition. Participant 5 (FoP) said the accreditation process is 'not a public process, but it is, if you like, a peer review process' where they will be: 'kind of grilled for three days by other academics and professional representatives'.

As in FoP, Participant 3 (E\&B) stated, 'professional bodies themselves set the curriculum area requirements'. However, Participant 4 (E\&B) elaborates on the influence of the professional bodies on curriculum design by describing the level of specificity of the PSs: 'it does vary by degree programme and sometimes it's implicit, sometimes it's explicit'. Further, there does not appear to be 'any direct or immediate monitoring going on of how the standards are defined and articulated, or how they're embedded into the curriculum'.

This suggests that E\&B accrediting bodies are more relaxed those of EDSW and Pharmacy. Moreover, E\&B has more autonomy in course design. Interestingly, SCM performance-based units have even greater autonomy in PSs. In fact, PS development for performance-based units might arguably be the most autonomous of the faculties studied.

Moreover, in the Music Education accreditation process, Participant 2 (SCM) explained that the department had to ensure they had covered 'all of the mandatory areas in our content' and 'each of the teaching elements that are prescribed by the New South Wales Institute of Teachers'.

Interestingly, the Music Education department is accredited by the same body as EDSW, the faculty with the least autonomy in course design. Moreover, Participant 2 said that most of the accreditation requirements had been met, they 'just had to articulate them'.

\subsection{Faculty Autonomy}

These interviews show variation in autonomy across faculty application of University GAs, as well as autonomy granted by accrediting bodies in the accreditation process. Differing levels of autonomy in accreditation processes is indicative of differences in autonomy in course development and AoL practices across faculties. 
Participant 1 (SCM) explained, 'there's quality assurance measures at the university itself, like unit of study evaluations', but that 'there's difficulty in quality assurance in the performance areas' due to the nature of one-to-one tuition. Moreover, this conflict, where 'it's been part of the university policy' that quality assurance is of units, it's not of teachers, even though quality assurance for Performance units of study cannot be done given the nature of the teaching.

As a result, Participant 1 (SCM) argues that the faculty is unable to "use standard evaluation in instruments [instrumental units of study]'. Nevertheless, participants describe high levels of autonomy in evaluation methods, stating, 'we have created one, but there is a problem to some extent in having it assessed because it's constantly seen as an evaluation of teachers'.

Participant $3(\mathrm{E} \& \mathrm{~B})$ describes the process regarding new subject additions or removals to an accredited curriculum, including 'substantial revision to content or assessment within a particular unit of study' where accrediting bodies require the faculty to: 'make a judgment about whether it is something that we need to inform them [accrediting body] about within their reporting requirements, or whether that's just considered as regular updating'.

This suggests a low level of autonomy in curriculum development, with a requirement that faculty must inform the accrediting body of major changes, but greater faculty flexibility in deciding the extent of change within reporting obligations.

Arguably, as a result of reporting obligations, the faculty has two approaches to curriculum review. First, formal faculty-level reviews result in reportable changes to accrediting bodies. Participant 3 (E\&B) notes, in these reviews 'we have external stakeholders who would be members of those review teams' and who 'tend to make more comment about content'. Second, curriculum review uses 'employer and professional engagement' where professional engagement stems from 'practitioners who teach in our programs as sessional lecturers' and focuses on 'evaluating communication tasks'.

Furthermore, Participant 3 (E\&B) also notes that, whilst accrediting bodies set the PSs, they do not 'set requirements like they [the students] have to get a particular level of performance within that content area'. This suggests that E\&B accrediting bodies influence course design, but allow faculty a level of autonomy to set measures of performance in relation to those standards. Inspection of E\&B exam papers by the accrediting body supports this statement. However, accrediting bodies do not 'look at the student's scripts and what grades they've got to give those scripts'. Participant 3 concludes, 'it doesn't really give you information about how hard is the marking'. Again, this suggests that E\&B have a low level of autonomy in course design, but a high level of autonomy in defining performance levels and measurement. In short, the E\&B accrediting body allows a high level of autonomy in assurance, in units of study with less defined professional standards, and in curriculum design, compared to SCM Music Education.

Participant 5 (FoP) notes, accrediting bodies 'don't micromanage the teaching of every course'. Rather, they concern themselves with whether the faculty 'can or can't provide graduates that would meet professional standard'. Equally, Participant 6 (FoP) states, 'we are 
not obliged to align any of our courses learning objectives with those professional standards' and 'there is no requirement for assessment task criteria etc., to be aligned with the professional standards'. This demonstrates the high level of autonomy in FoP course design and AoL.

This could be due to the FoP accreditation format in which graduates are required to complete an internship prior to accreditation examinations, and the university is formally responsible for a point, not well defined really, in terms of their professional practices' [Participant 5]. Regarding this undefined point of responsibility, Participant 5 notes that 'there is a healthy professional debate about where the responsibilities sort of start and stop'. Arguably, this grey area is analogous to a lack of articulation in PSs, which allows greater faculty autonomy, particularly with AoL. This is suggested by the faculty's professional engagement in defining these boundaries and relates to accreditation and AoL.

Discussing external methods in curriculum reviews, Participant 5 states 'the only way you can do that in an objective and equitable way is have some external approaches'. This suggests, whilst there is a greater level of autonomy in learning outcomes, arguably because more views are considered during the accreditation process, particularly from those with an interest in graduate learning outcomes (i.e. internship employers), the faculty has less autonomy than that mandated by the accrediting body. Moreover, Participant 6 (FoP) states 'we don't know the accreditation details at our unit of study level', suggesting accreditation is at a higher level and thereby allows greater autonomy at unit of study level.

Participant 7 (EDSW) noted, since 2008 'all social work programs [had] to meet the requirements of the national policy'. This indicates that some faculty-level autonomy had been taken away following the introduction of national standards. Furthermore, Participant 7 notes that accreditation involves an 'external panel that comes in [to the faculty]', consisting of academics and field practitioners, who look at 'what we deliver, how we deliver and its outcomes'. Equally, Participant 8 (EDSW) observed that the faculty must 'provide a massive amount of documentation' to accrediting bodies.

Participant 8 (EDSW) indicates that Education has reduced autonomy in course design due to PSs, where the 'standards in fact are driving everything that we do'. Moreover, in contrast to FoP, the NSWIT micromanages the course. Participant 8 notes, 'even the discourse of our documents is now being determined by an outside standards authority'. The result of NSWIT micromanagement is threefold: 'in some instances, we've had to change the number of hours that we teach'; NSWIT has 'taken away a great deal of academic freedom from us about how we devise our programs'; and NSWIT dictates 'the kinds of students they are allowed to admit' into the course [Participant 8]. This demonstrates that in EDSW, Education has limited autonomy in many areas of curriculum development and teaching compared to SCM, E\&B, and FoP, with the exception of admissions.

\subsection{Faculty Accountability}

The previous section identified varying degrees of faculty autonomy in addressing PSs, GAs, curriculum design, and assurance of learning. Participant 5 (FoP) stated that university GAs 
are required in their course materials in order for the 'academic board to sign off' the degree, thereby raising the issue of 'accountability' in the curriculum implementation process. Participant 1 (SCM) noted the 'collective part in arriving at standards, not just top down', thereby implying a shared accountability of PSs amongst performance-based units. Moreover, Participant 1 also sees shared accountability in GA development, where GAs are determined by a 'learning and teaching committee': for example, during teaching and learning evaluation, 'there's an informal process, forums with students for example, the usual undergraduate committee structures'. This suggests that the SCM approach to developing faculty-derived GAs, and unit-based PSs in performance-based units, allows collective accountability in teaching and learning outcomes. Moreover, by evaluating these with students, they demonstrate an awareness of accountability to students.

With regard to the alignment of PSs with learning outcomes in Music Education, Participant 2 (SCM) indicates these are 'documented in this accreditation document, which each individual person working on a unit of study has developed for their own unit of study'. This suggests more individual accountability in aligning PSs with learning outcomes. However, it is not mentioned whether the inclusion of this evidence is peer-reviewed internally prior to inclusion.

Although the task of alignment has decentralized to program directors and given that, as identified in the previous section, E\&B have a high level of autonomy within the university GA structure to redefine university GAs for their course design (as seen in the SCM's approach), it is possible that: (a) program directors have not considered university-based faculty GAs as a possible approach to alignment; (b) program directors do not consider the university GAs important; (c) program directors believe university GAs are addressed in their professional standards; or (d) on the basis of accountability, the associate dean, rather than program directors, must clarify the alignment to the university.

Regarding faculty alignment with PSs and GAs, Participant 4 (E\&B) notes, 'if there's a match fine, if there's not, then we go with what we think should be there'. If that happens to 'harmonize with what the university says generic bachelors or masters' students should have, fine. If it doesn't, well it doesn't matter contextualising this as desired program-specific graduate learning outcomes'.

In the FoP, Participant 6 reported that there are three levels of accountability in the university and internship process. The first is at faculty level where 'within the discipline, there are discipline heads and then the associate dean and the dean who would be responsible for learning outcomes and accreditation'. The second is at the professional level, where professional practitioners taking graduate interns are accountable for providing them with the appropriate training to pass the accreditation examinations. The third level involves both university and professional practitioners. The university ensures the graduate has met all PSs and is prepared for internship, whereas professional practitioners provide feedback to the university to assist in student development.

Participant 7 (EDSW) highlights the importance of national accreditation in social work, and faculty responsibility to students. This participant knew of 'two schools of social work that 
have been de-accredited and that means that the students - the graduates of that program, can 't apply for jobs that require a qualified social worker'. As a result, those students were forced to change to accredited universities.

The previous section showed that, given the level of NSWIT control, Education has reduced autonomy, arguably because NSWIT prescribe almost every aspect from program documentation to student admissions. However, in relation to GAs, Participant 8 (EDSW) suggested that the focus on PSs meant that GAs were not at the forefront of program development. Referring to GA accountability, in response the question 'can I ask how then you will respond at the university level to their apparent absence?', Participant 8 (EDSW) said 'it would be a level above me who would be looking at this'. This suggests in education, as in $\mathrm{E} \& \mathrm{~B}$, more senior members of the faculty are accountable to the university regarding GAs.

\section{Discussion}

The findings described in this paper show how there are a variety of different interdependent factors that must be taken into account by a university faculty when developing new curricula, however underlying these factors, are three core elements. These are program restraints, program design and implementation and program assurance.

\subsection{Program Constraints}

The first core element relates to external influences, or 'program constraints' and can be considered to be factors that create a framework which sets out program design approaches: for example, many of the respondents highlighted considerations relating to university policy, whilst other considerations highlighted external influences - industry specific and governmental criteria that were in many cases, beyond university and faculty control. In the area of program constraints, there are three factors: new students, the university, and accrediting bodies.

Arguably, new students are the most fundamental of program constraints (with no new students there would be no course). The faculty of E\&B described how they considered the marketing and branding of courses to new students as an important aspect of course design, in the context of the generic university GAs.

GAs affecting the second factor, 'the University', was identified in E\&B with 'reputation' underlying how professional practitioners felt about the University's graduates, which in turn could affect University policy, spending. How PSs affected the university was seen in social work, where prior to the embedding of PSs in national policy, each university was responsible for their documentation. Furthermore, PSs affect the university when a faculty member is on a professional standards committee (FoP), and was acknowledged that University Staff members would sit on a committee in a professional capacity. How industry professionals impact the University was highlighted by the E\&B benchmarking procedure where employers' provide reports on the number of graduates to reach various stages in interview and employment, and such a comparison is done at university level. These statistics can alter the perceptions of the university both from a new student perspective and potential employer 
perspective.

The final factor contained within program constraints is the accrediting bodies. Industry professionals affect the accrediting bodies in FoP, where there is extensive consultation with the industry to arrive at PSs. This can also be seen in E\&B where industry professionals also teach at the faculty, and have input to assessment tasks. Course accreditation is also another consideration of the accrediting body. Examples of this are in EDSW, FoP, SCM (performance-based units of study), and E\&B, where the course must be accredited. However, given the unique nature of the individual post-industry placement accreditation process in FoP, an additional consideration is required in accreditation. The Accrediting bodies also have to consider the suitability of the PSs to current industry practice and modify them as required.

\subsection{Program Design and Implementation}

The second core element contained is Program Design and Implementation, and how faculties manage the interests of the key constraints. Within this core area, there are three main factors: GAs, the Faculty, and PSs. In between these three factors are three faculty specific determinants in program design and implementation (or 'three As'): Autonomy, Accountability and Alignment. In terms of GAs, in E\&B, and in social work, and had recently been adopted by FoP, but was not done in education since a recent change in the accreditation process.

Concerning the GAs, the relationship between the wider university and the faculty is implied in that each faculty must include the University GAs in their curriculum, and furthermore, there appears to be reporting obligations surrounding this as indicated by Education and E\&B. Furthermore, the University not only provides funding to the faculties, but also sets out policy documents and guidelines for best practice, which are generic and cross faculty, and must be adhered to by each faculty.

Accrediting bodies affect the faculties in different ways, thus no direct comparison can be made across the faculties. There are some similarities between some aspects of the accreditation processes in some of the faculties, but generally, accreditation processes are different. For example, some accrediting bodies perform site visits (FoP), others do not (Education); some inspect the exam papers $(\mathrm{E} \& \mathrm{~B})$, others do not $(\mathrm{SCM})$; some accrediting bodies require the faculty to inform them of a new course (E\&B), others do not (SCM); some accreditations are peer-reviewed (FoP), some are not (Education).

Regarding accreditation, there is a sharp contrast between social work and FoP in enforcement of penalties for failure to comply with PSs, where social work accrediting bodies will close the courses down with immediate effect. In contrast, FoP obtains transitional accreditation for up to three years for new courses, as they require graduates to accredit a course.

\subsection{Program Assurance}

The third core element is Program Assurance, and relates program perception, assessment, benchmarking or accreditation. Within this core element there are four key factors: existing 
students, industry professionals, course accreditation and graduate accreditation. E\&B regularly assessed students with tasks that could be considered aligned with the GAs: for example, communication tasks that are considered learning outcomes that align with GAs. It is also expected that upon course completion, the student will have all of the GAs specified by the course. This is particularly relevant when considering the FoP's course format, where students are deemed to have GAs and build upon them in their course before learning external professional practice prior to becoming industry professionals.

Industry professionals in some faculties (SCM performance-based units, social work, FoP and E\&B) have a very direct influence on both existing students and graduates in two ways. In some faculties industry professionals teach students and assess the students, whilst in others, the industry professionals take existing students for work experience (social work, SCM).

GAs also affects industry professionals, where GAs in social work are communicated to the industry professionals prior to accepting an existing student on work experience. These GAs are said to help communicate course goals, student skills, and university image. The Industry Professionals relationship with PSs is twofold. In one sense industries are controlled by PSs to ensure public health and safety or to ensure the quality of care or service, by ensuring that practitioners meet prescribed standards, which, in some instances, are co-developed by industry professionals. Types of PSs differ across faculties depending on the discipline, and as such require different accreditation approaches.

These approaches can be seen by the inclusion of course accreditation and graduate accreditation into the core element of program assurance. In education, the NSWIT only accredits the course; therefore a student is registered if they meet the minimum requirements for attendance and assessment. The courses are also accredited in SCM (music education), E\&B, EDSW (social work), and in FoP. However, in FoP, they do not gain accreditation from the PSA upon completion of the course. Instead they have to complete an internship and complete an exam before being accredited individually. This is outside of the university scope for FoP courses.

\section{Conclusion}

Having briefly discussed the relationships between the elements of GAs, PS's and AOL, it can be concluded that there are significantly different approaches to course design and implementation, and program assurance across the four faculties in this University. Each faculty having different levels of each of the 'Three As': Autonomy, Accountability, and Alignment (between GAs and PSs), each being determined by faculty situation specifics.

Across the three As, Alignment in GAs and PSs is highly faculty specific and is the cause of the greatest tension between GAs and PSs. Accountability also differed across the faculties, and despite different interpretations of accountability within faculty hierarchy, the differences were as a result of internal processes rather than external influences (i.e. accrediting bodies), as the university hierarchy is consistent across all faculties. Faculty levels of autonomy in course development also made a difference. A more aligned aspect of autonomy was in program assurance, and how the faculty assessed and marked the students, and exploited their 
autonomy of assurance to improve student and course development, and industrial relations.

This area of least disparity between the faculties, (levels of autonomy of AoL and accreditation), is an interesting research area that could assist in cross faculty management and implementation of generic assurance of learning processes at university level. This paper has reported results of interviews with those responsible for teaching and learning in four faculties at an Australian University. The results indicated that curriculum developers are often unable to align the GAs and PSs which, in turn, creates challenges for an AOL.

\section{References}

Barrie, S. C. (2006). 'Understanding what we mean by the generic attributes of graduates', Higher Education, 51, 215-241. http://dx.doi.org/10.1007/s10734-004-6384-7

Barrie, S. C. (2007) 'A conceptual framework for the teaching and learning of graduate attributes', Studies in. Higher Education, 32(4), 439-458. http://dx.doi.org/10.1080/03075070701476100

Bath, D., Smith C., Stein, S., \& Swann, R. (2004). 'Beyond mapping and embedding graduate attributes: bringing together quality assurance and action learning to create a validated and living curriculum', Higher Education Research and Development Journal, 23(3), 313-328. http://dx.doi.org/10.1080/0729436042000235427

Beck, J. (2008). 'Governmental Professionalism: Re-Professionalising or De-Professionalising Teachers in England?'. British Journal of Educational Studies, 56(2), 119-143. http://dx.doi.org/10.1111/j.1467-8527.2008.00401.x

Beck, J. (2009). 'Appropriating professionalism: restructuring the official knowledge base of England's 'modernised' teaching profession', British Journal of Sociology of Education, 30(1), 3-14. http://dx.doi.org/10.1080/01425690802514268

Berdrow, I. (2008). 'Lessons Learned: Assurance of Learning Is Primarily About Learning', Not Assurance. Assessment Update: Progress, Trends and Practices in Higher Education, 20(5), 1-2; 15-16.

Cohen, L., Manion, L.\& Morrison, K. (2001). Research Methods in Education (5th ed.). London: Routledge Falmer.

Cameron, H. (2001). 'Monitoring standards for professional education', Journal of Vocational Education \& Training, 279-300. http://dx.doi.org/10.1080/13636820100200154

De la Harpe, B., and Radloff, A. (2008). 'Developing graduate attributes for lifelong learning: how far have we got?' In D. Orr, P. A. Danaher, G. Danaher \& R. E. Harreveld (eds.), Lifelong Learning: reflecting on successes and framing futures, Keynote and refereed papers from the 5th International Lifelong Learning Conference (pp. 136-141). Rockhampton: Central Queensland University Press

Edwards, S. (2005). 'Higher Education in the Twenty-first Century: examining the interface 
between graduate attributes, online and problem-based learning at Monash University', Technology, Pedagogy and Education, 14(3), 329-352. http://dx.doi.org/10.1080/14759390500200210

Gillard, D. (2005). 'Rescuing Teacher Professionalism', Forum, 47(2), 175-180. http://dx.doi.org/10.2304/forum.2005.47.2.7

Harvey, A., and Kamvounias, P. (2008). 'Bridging the implementation gap: a teacher-as-learner approach to teaching and learning policy', Higher Education Research and Development, 27(1), 31-41. http://dx.doi.org/10.1080/07294360701658716

Johnston, B., and Watson, A. (2004). 'Participation, reflection and integration for business and lifelong learning: Pedagogical challenges of the integrative studies programme at the University of Strathclyde Business School', Journal of Workplace Learning, 16(1/2), 53-62. http://dx.doi.org/10.1108/13665620410521512

Kelley, K. A., McAuley, J. W., Wallace, L. J., \& Frank, S. G. (2008). 'Curricular Mapping: Process and Product', American Journal of Pharmaceutical Education, 72(5), 1-7. http://dx.doi.org/10.5688/aj7205100

Kilpatrick, J., Lund Dean, K., \& Kilpatrick, P. (2008). 'Philosophical Concerns About Interpreting AACSB Assurance of Learning Standards', Journal of Management Inquiry, 17(3), 200-212. http://dx.doi.org/10.1177/1056492607312024

McNay, I. (2007). 'Values, Principles and Integrity: Academic and Professional Standards in UK Higher Education', Higher Education Management and Policy, 19(3), 1-22. http://dx.doi.org/10.1787/hemp-v19-art17-en

Morley, C., and Macfarlane, S. (2010). 'Repositioning Social Work in Mental Health: Challenges and Opportunities for Critical Practice', Critical Social Work, 11(2), 46-59.

Oliver, B. (2011). 'Assuring Graduate Capabilities', Paper presented at ALTC National Teaching Fellowship, Forum, Curtin University, Perth, $19^{\text {th }}$ October 2011. Retrieved from http://api.ning.com/files/4NVLwCQJCAaY6dOzF0QUX6YeHoMYH10FsP-NSJ8gpUQ-c5N XRq85RyUSOJCMSorSXTJYb2YrVB8H1D4aNzDegsBVHCNF6nH3/keyslides10may.006. png.

Pokharel, A. (2007). 'Interview with Kathryn Martell: "Assurance of Learning (AoL) Methods Just Have to be Good Enough"', Journal of Education for Business, 82(4), 241-243. http://dx.doi.org/10.3200/JOEB.82.4.241-243

Stoesz, D., and Karger, H. J. (2009). 'Reinventing Social Work Accreditation', Research on Social Work Practice, 19(1), 104-111. http://dx.doi.org/10.1177/1049731507313976

Treleaven, L., and Voola, R. (2008). 'Integrating the development of graduate attributes through constructive alignment', Journal of Marketing Education, 30(2), 160-167. http://dx.doi.org/10.1177/0273475308319352 
Note

1 Support for this activity has been provided by the University of Sydney Teaching Improvement and Equipment Scheme (TIES).

\section{Copyright Disclaimer}

Copyright reserved by the author(s).

This article is an open-access article distributed under the terms and conditions of the Creative Commons Attribution license (http://creativecommons.org/licenses/by/3.0/). 